
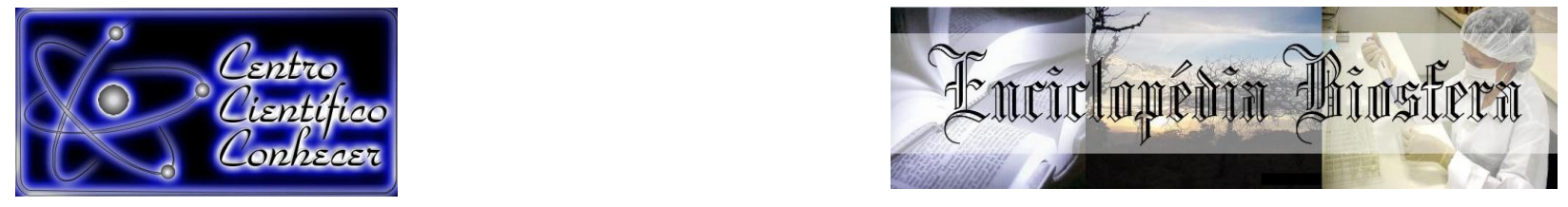

\title{
HEMANGIOSSARCOMA CUTÂNEO COM METÁSTASE PULMONAR EM CADELA DA RAÇA PITBULL - RELATO DE CASO
}

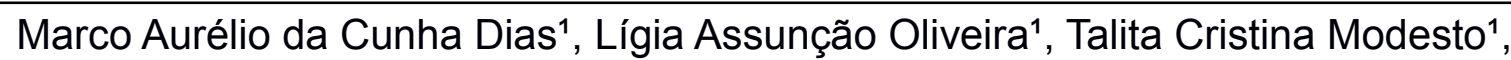
Fernando Dedding Martins ${ }^{2}$, Marcio de Barros Bandarra ${ }^{3}$

1 - Médico Veterinário Residente em Patologia Animal, Universidade Federal de Uberlândia, Uberlândia-MG, Brasil. E-mail: maureliocdias@gmail.com

2 - Mestrando pelo programa de Pós-graduação em Ciências Veterinárias da Universidade Federal de Uberlândia, Uberlândia - MG, Brasil.

3 - Professor doutor em Patologia Animal, Faculdade de Medicina Veterinária, Universidade Federal de Uberlândia, Uberlândia - MG, Brasil.

Recebido em: 06/04/2018 - Aprovado em: 10/06/2018 - Publicado em: 20/06/2018 DOI: 10.18677/EnciBio 2018A53

\begin{abstract}
O hemangiossarcoma cutâneo é uma neoplasia maligna de células endoteliais dos vasos da derme ou subcutâneo. Nos cães, a forma cutânea é menos agressiva que a visceral, apresentando menor potencial metastático. Macroscopicamente, são massas avermelhadas, amarronzadas ou enegrecidas. O diagnóstico citopatológico de hemangiossarcoma é difícil, pois nos aspirados citológicos observa-se elevada quantidade de hemácias e poucas células neoplásicas. Assim, o diagnóstico definitivo de hemangiossarcoma pode somente ser feito através da histopatologia. $O$ objetivo deste trabalho foi relatar a ocorrência de metástase pulmonar em uma cadela pitbull com hemangiossarcoma cutâneo. O animal apresentava nodulações em região ventral de abdome e tórax, aderidas à pele, de coloração vermelho enegrecida, medindo entre $1 \mathrm{~cm}$ e $10 \mathrm{~cm}$. Na necropsia, os pulmões apresentavam pontos milimétricos, vermelho-escuros, por toda superfície. Foram coletados fragmentos das massas cutâneas e pulmões para confecção das lâminas histológicas. Ao exame histopatológico diagnosticou-se hemangiossarcoma cutâneo e metástase pulmonar de hemangiossarcoma.
\end{abstract}

RESUMO

PALAVRAS-CHAVE: endotélio, histopatologia, neoplasia.

\section{CUTANEOUS HEMANGIOSARCOMA WITH PULMONARY METASTASIS IN A PITBULL BREED BITCH - CASE REPORT}

\begin{abstract}
Cutaneous hemangiosarcoma is a malignant neoplasm of endothelial cells of the vessels from dermis or subcutaneous. In dogs, the cutaneous form is less aggressive than the visceral form, presenting less metastatic potential. Macroscopically, they are reddish, brownish or blackish masses. The cytopathological diagnosis of hemangiosarcoma is difficult, because in the aspirates is observed high quantity of red blood cells and few neoplastic cells. Thus, the definitive diagnosis of hemangiosarcoma can only be made through histopathology. The objective of this study was to report the occurrence of pulmonary metastasis in a pitbull breed bitch with cutaneous hemangiosarcoma. The animal presented nodulations in the ventral
\end{abstract}


region of abdomen and thorax, adhered to the skin, of dark red color, measuring between $1 \mathrm{~cm}$ to $10 \mathrm{~cm}$. At necropsy, the lungs had milimetric points, dark red, all over the surface. Fragments of cutaneous masses and lungs were collected for the preparations of histological slides. In the histopathological examination, was diagnosed cutaneous hemangiosarcoma and pulmonary metastasis.

KEYWORDS: endothelium, histopathology, neoplasm.

\section{INTRODUÇÃO}

A pele é composta por diferentes camadas e estruturas, sendo suscetível a diversos tipos de neoplasias, estando os tumores de pele entre os mais frequentes na medicina veterinária. Estes podem ser de origem epitelial ou mesenquimal. Nos tumores mesenquimais estão inclusos aqueles originados do tecido de sustentação da derme e subcutâneo (tecido conjuntivo fibroso, vasos sanguíneos e linfáticos, tecido adiposo e nervos) e os tumores de células redondas (DALECK ; DE NARDI, 2016; HENDRICK, 2017).

Dentre as neoplasias mesenquimais cutâneas está o hemangiossarcoma, um tumor maligno, que se origina das células endoteliais dos vasos sanguíneos. Além de ocorrer na pele, este tumor pode ocorrer primariamente em outros órgãos, apresentando-se isolado ou na forma multicêntrica, quando acomete vários órgãos internos simultaneamente (ROSENTHAL, 2004; HENDRICK, 2017). Quando se compara a frequência de hemangiossarcomas não viscerais e viscerais, a pele é mais frequentemente acometida (FLORES , 2016; SOARES et al., 2017).

Nos cães, os locais de maior ocorrência são o tronco e membros e, de modo geral, hemangiossarcomas cutâneos são menos agressivos que os viscerais, apresentando menor potencial metastático e maior sobrevida do animal (HENDRICK, 2017). A causa desse tipo de tumor é desconhecida, mas parece haver relação com irradiação solar crônica. Raças de cães com pelo curto e pele pouco pigmentada são mais predispostas, como os whippets, greyhounds e pitbulls ( HARGIS et al., 1992; HENDRICK, 2017). Em um estudo realizado por Soares et al. (2017), o pitbull foi a raça mais acometida por hemangiossarcomas.

Os hemangiossarcomas cutâneos podem se originar nos vasos sanguíneos da derme ou subcutâneo. Normalmente apresentam-se como uma massa isolada e bem definida, de coloração vermelha, amarronzada ou enegrecida, de consistência macia a firme e que flui sangue quando cortado. Tumores mais agressivos são mais infiltrativos e pobremente delimitados, invadindo tecidos vizinhos (HENDRICK, 2017).

O diagnóstico citopatológico de hemangiossarcoma é difícil, pois os aspirados costumam vir com elevada quantidade de hemácias e poucas células neoplásicas, no entanto, alguns tumores podem esfoliar muitas células. Quanto à morfologia celular, normalmente nos aspirados de hemangiossarcoma, são visualizadas células mesenquimais pleomórficas, isoladas ou em grupos. Porém, esse achado isoladamente não tem significância, pois podem se tratar de células mesenquimais reativas de um hematoma, por exemplo. Outros achados importantes que podem auxiliar no diagnóstico citopatológico de hemangiossarcomas são a presença de eritrofagocitose e de células hematopoiéticas nas amostras (VALENCIANO; COWELL, 2013).

Histologicamente há grande pleomorfismo entre as células neoplásicas, que variam de fusiformes a poligonais ou ovoides, e normalmente se organizam formando fendas ou canais vasculares. As células apresentam grandes núcleos, que são hipercromáticos, com presença de anisocariose acentuada e figuras de mitose 
são frequentemente visualizadas. Em algumas áreas, o estroma entre as fendas é acelular, hialino e eosinofílico. Pode haver áreas intensamente celulares que são difíceis de distinguir de sarcomas pouco diferenciados ou áreas com grande quantidade de sangue e poucas células neoplásicas, mimetizando um hematoma. Pode ocorrer também em uma forma incomum, chamada epitelioide, em que a formação vascular é discreta e as células neoplásicas apresentam formato poliédrico colunar, dando ao tumor uma aparência glandular (HENDRICK, 2017).

O pulmão é um sítio de eleição para metástases de tumores malignos, pois os capilares pulmonares são o primeiro filtro que êmbolos neoplásicos presentes na veia cava ou artéria pulmonar encontram. As aparências das metástases variam conforme o tumor primário. Nódulos císticos avermelhados contendo sangue em seu interior são indicativos de hemangiossarcoma (ZACHARY ; MCGAVIN, 2016).

O tratamento mais indicado é a excisão cirúrgica, acompanhada de tratamento quimioterápico, utilizando fármacos como a oxorrubicina, vincristina e ciclofosfamida. No caso de tumores limitados a derme, o prognóstico é bom após a excisão. Já naqueles do subcutâneo, varia de reservado a desfavorável, pela capacidade de invasão e metástase do tumor (HNILICA, 2016). O presente estudo teve por objetivo relatar a ocorrência de metástase pulmonar em uma cadela com hemangiossarcoma cutâneo, necropsiada no Setor de Patologia Animal do Hospital Veterinário da Universidade Federal de Uberlândia.

\section{RELATO DE CASO}

No dia 06 de novembro de 2017, deu entrada no Hospital Veterinário da Universidade Federal de Uberlândia (HV-UFU) uma cadela de 13 anos, da raça Pitbull, de pelagem preta e pesando $26,8 \mathrm{~kg}$. A queixa que motivou a consulta foi a presença de nodulações em região abdominal. O tutor do animal relatou que estas nodulações haviam surgido há aproximadamente dois meses, com crescimento progressivo e que o animal as lambia com frequência.

Macroscopicamente, estas nodulações encontravam-se em região ventral de abdome e tórax, eram aderidas à pele, de coloração vermelho enegrecida, consistência macia e superfície irregular, medindo entre $1 \mathrm{~cm}$ e $10 \mathrm{~cm}$ e muitas destas se encontravam ulceradas. Além disso, a cadela apresentava-se prostrada, com dificuldade de locomoção, desidratada e desnutrida.

\section{RESULTADOS E DISCUSSÃO}

Ao hemograma, a cadela apresentava a contagem de hemácias de $2,51 \times 10^{6} / \mathrm{mm}^{3}$ e os valores de hemoglobina de $5,8 \mathrm{~g} \%$ e hematócrito $17,4 \%$, caracterizando uma anemia, por estarem abaixo dos valores considerados normais para um cão (JAIN, 1993). Em um estudo realizado por Wong et al. (2015) em cães com hemangiossarcoma, anemia foi a alteração hematológica mais frequente, estando presente em $78 \%$ dos animais.

O primeiro exame realizado pelo Setor de Patologia Animal do Hospital Veterinário da Universidade Federal de Uberlândia foi o citopatológico, no mesmo dia que o animal deu entrada no hospital. Foi feita a coleta por Punção por Agulha Fina (PAF) em diferentes nodulações e preparado o esfregaço. As lâminas foram coradas com coloração Panótico Rápido (Renylab ${ }^{\circledR}$ ) e em seguida foram feitas as leituras em microscópio óptico. Em todas as lâminas foi observada elevada quantidade de hemácias e moderada a escassa quantidade de células mesenquimais neoplásicas. Estas apresentavam formato fusiforme, se encontrando isoladas, por vezes agrupadas, possuindo citoplasma amplo, núcleo alongado e 
central, com cromatina frouxa e nucléolo evidente. Foi notado também elevado pleomorfismo celular, com elevada anisocitose e anisocariose (Figura 1). Apesar dos achados macro e microscópicos serem altamente sugestivos de hemangiossarcoma, foi dado o diagnóstico de neoplasia mesenquimal maligna indiferenciada e sugerido o encaminhamento do material para análise histopatológica, pois a diferenciação do hemangiossarcoma de outras neoplasias, tanto benignas quanto malignas, pode ser feito apenas através da histopatologia (NELSON ; COUTO, 2015).

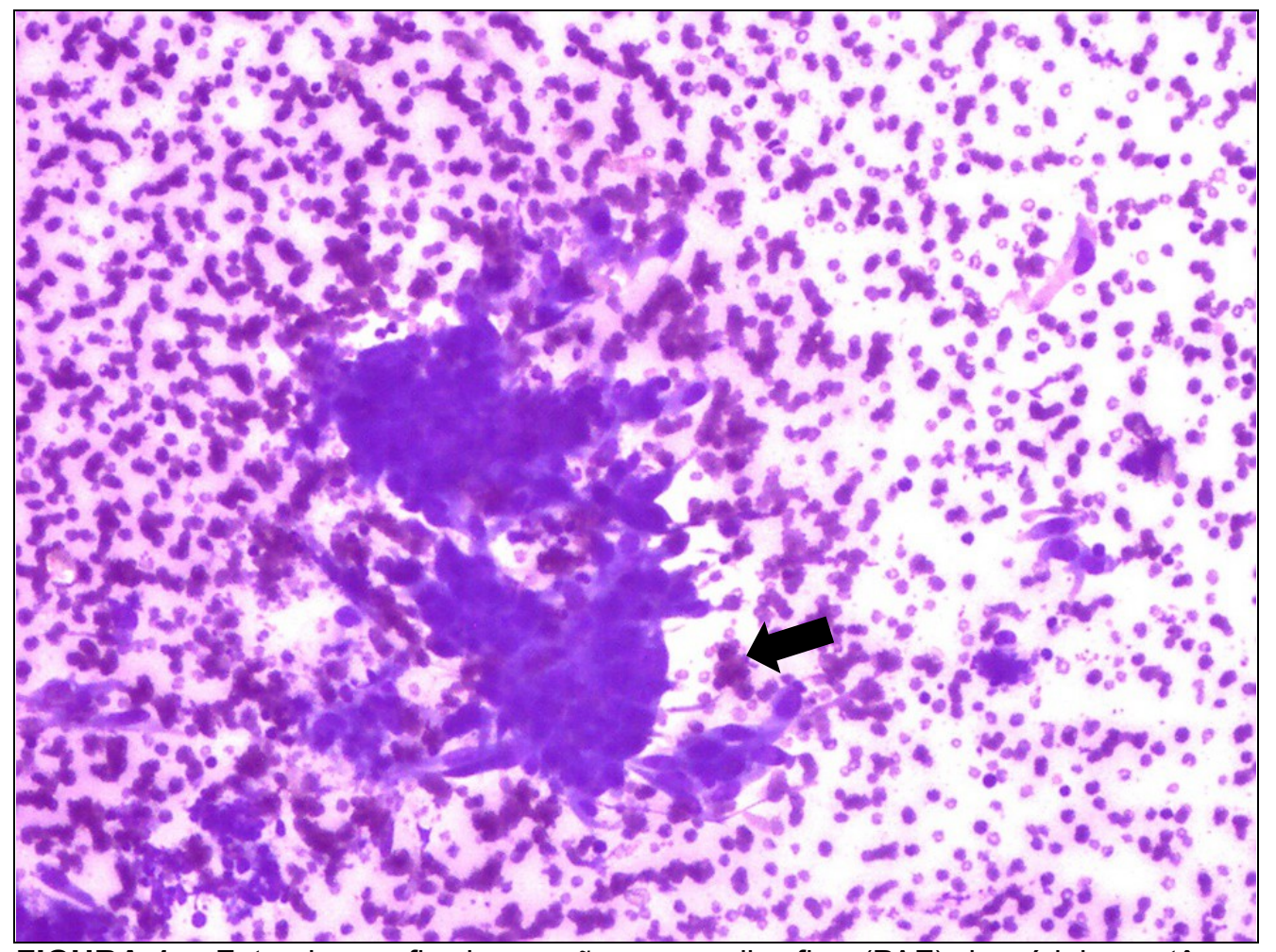

FIGURA 1 - Fotomicrografia de punção por agulha fina (PAF) de nódulos cutâneos em cadela da raça Pitbull. Nota-se a presença de grupo de células mesenquimais, apresentando formato fusiforme, citoplasma amplo, núcleo alongado e central, com cromatina frouxa e nucléolo evidente (seta preta). Panótico rápido $\left(\right.$ Renylab $\left.^{\circledR}\right)$, objetiva de 10X.

O animal apresentou piora progressiva com o passar dos dias, e o tutor optou pela eutanásia. Após o procedimento, a cadela foi encaminhada ao Setor de Patologia Animal, para realização do exame de necropsia. O animal foi necropsiado no mesmo dia do óbito, estando em bom estado de conservação.

Ao exame externo, observou-se a presença de elevada quantidade de nodulações cutâneas, de cor avermelhada, consistência macia e superfície irregular. em região de abdome e tórax ventrais (Figura 2a). Ao corte, a maior das nodulações, que tinha aproximadamente $10,0 \mathrm{~cm}$, apresentava superfície irregular, com a periferia de coloração avermelhada e região mais central esbranquiçada, além de fluir discreta quantidade de líquido avermelhado espesso (Figura 2b), compatível com as descrições macroscópicas de hemangiossarcoma presentes na literatura (HARGIS et al., 1992; HENDRICK, 2017).

Ao abrir a cavidade torácica notou-se que ambos os pulmões apresentavam elevada quantidade de pontos milimétricos, de coloração vermelho-escura, distribuídos multifocalmente pela superfície, que se aprofundavam ao corte (Figura 
2c). Foi constatada também a presença de vários outros pontos de aspecto idêntico, mais profundamente no parênquima pulmonar.

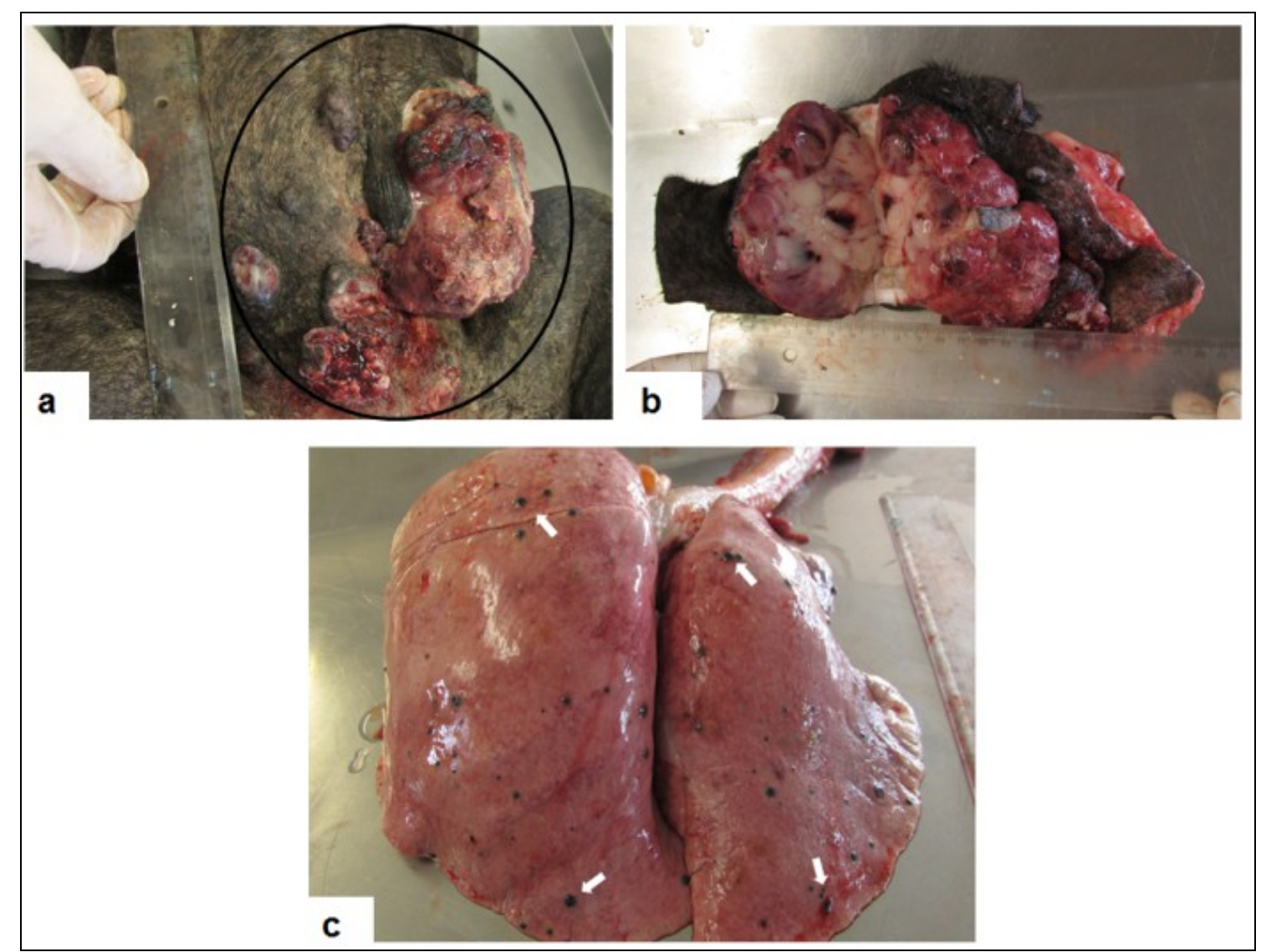

FIGURA 2 - a. Em destaque (círculo preto), presença de nodulações em região abdominal ventral, de coloração avermelhada, superfície irregular e, por vezes ulceradas; b. Ao corte, a maior das nodulações apresentava superfície irregular, com a periferia de coloração avermelhada e região central esbranquiçada; c. Pulmão com presença de pontos milimétricos, de coloração vermelho-escura, distribuídos multifocalmente por sua superfície (setas brancas).

Foram coletados fragmentos das massas cutâneas e pulmões, que foram fixados em formol $10 \%$ tamponado por 48 horas. Então, o material foi enviado ao Laboratório de Histopatologia da Universidade Federal de Uberlândia, onde foi processado rotineiramente para confecção das lâminas histológicas, que foram coradas com hematoxilina e eosina.

Nos fragmentos da massa cutânea, microscopicamente foi observada proliferação em derme de células de formato fusiforme, com núcleo apresentando cromatina frouxa e nucléolo evidente e elevada anisocitose e anisocariose. As células neoplásicas se organizavam na forma de fendas e cavernas, que se encontravam preenchidas por elevada quantidade de hemácias (Figura 3a), conforme descrito por Hendrick (2017), levando ao diagnóstico de hemangiossarcoma cutâneo. Já nos fragmentos de pulmão foi observada perda da arquitetura histológica do órgão, com substituição do parênquima pulmonar por células fusiformes, com núcleo apresentando cromatina frouxa e nucléolo evidente e elevada anisocitose e anisocariose, formando fendas e cavernas preenchidas por hemácias (Figura 3b), sendo compatível com metástase pulmonar de hemangiossarcoma. 
Apesar da literatura descrever o hemangiossarcoma cutâneo como menos agressivo que o visceral (HENDRICK, 2017), no caso desta cadela o tumor apresentou elevada agressividade, provocando metástase pulmonar. Tal agressividade pode ter contribuído para a rápida piora clínica do animal, o que culminou na eutanásia, uma vez que neoplasias malignas são causas frequente de morte e eutanásia em cães (FIGHERA et al., 2008).

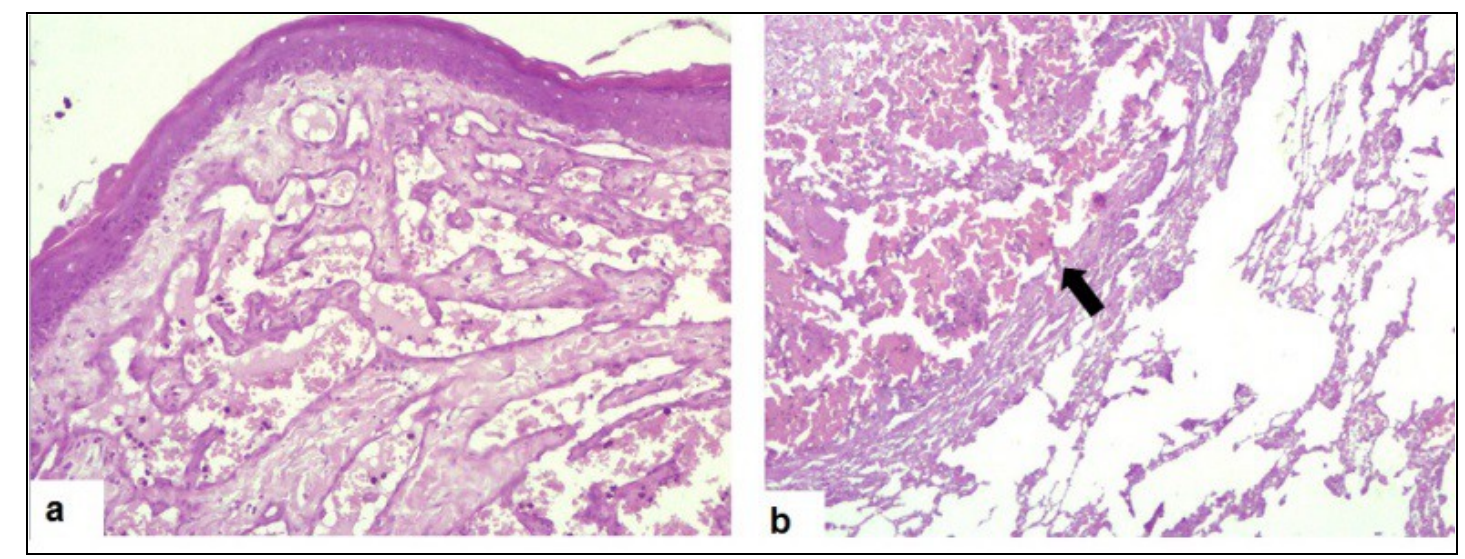

FIGURA 3 - a. Fotomicrografia de corte histológico de nódulo cutâneo. Nota-se proliferação em derme de células fusiformes, com núcleo apresentando cromatina frouxa e nucléolo evidente e elevada anisocitose e anisocariose, formando fendas preenchidas por hemácias. Hematoxilina e eosina, objetiva de 10X. b. Fotomicrografia de corte histológico de pulmão. Há perda da arquitetura histológica do órgão, com substituição do parênquima pulmonar por células fusiformes, com núcleo apresentando cromatina frouxa e nucléolo evidente e elevada anisocitose e anisocariose, formando cavernas preenchidas por hemácias (seta preta). Hematoxilina e eosina, objetiva de $10 \mathrm{X}$.

\section{CONCLUSÃO}

Com este relato conclui-se que o hemangiossarcoma cutâneo, apesar de descrito como menos agressivo que o visceral, pode provocar metástase em órgãos internos, o que tem por consequência um pior prognóstico e menor sobrevida do animal, mesmo após excisão cirúrgica da neoplasia cutânea. Assim, faz-se necessário a realização de exames complementares, em especial de imagem, para a verificação de possíveis metástases em cães com hemangiossarcomas cutâneos, garantindo uma melhor abordagem terapêutica do paciente e consequentemente uma sobrevida maior.

\section{REFERÊNCIAS}

DALECK, C. R., DE NARDI, A. B. Oncologia em cães e gatos . Grupo Gen-Editora Roca Ltda., 2016.

FIGHERA, R. A., SOUZA, T. M., SILVA, M. C., BRUM, J. S., GRAÇA, D L., et al. Causas de morte e razões para eutanásia de cães da Mesorregião do Centro Ocidental Rio-Grandense. Pesquisa Veterinária Brasileira, v. 28, n. 4, p. 223-230, 2008. Disponível em: <https://doi.org/10.1590/S0100-736X2008000400005>. DOI: $10.1590 / \mathrm{S} 0100-736 \mathrm{X} 2008000400005$

FLORES, M. M. Aspectos epidemiológicos do câncer em cães da região central do Rio Grande do Sul: 50 anos (1964-2013). 2016. Tese de Doutorado. Universidade Federal de Santa Maria. 
HARGIS, A. M., IHRKE P. J., SPANGLER W. L., STANNARD, A. A. A retrospective clinicopathologic study of 212 dogs with cutaneous hemangiomas and Hemangiosarcomas. Veterinary Pathology, v. 29, n. 4, p. 316-328, 1992. Disponível em: <https://doi.org/10.1177/030098589202900406> DOI: $0.1177 / 030098589202900406$

HENDRICK, M. J. Mesenchymal Tumors of the Skin and Soft Tissues. In: D. J. Meuten (Ed.), Tumors in Domestic Animals, $5^{\mathrm{a}}$ ed, lowa State Press, Ames, 2017, pp. 142-175.

HNILICA, K. A. Small Animal Dermatology: A Color Atlas and Therapeutic Guide. $4^{\text {a }}$ ed. Elsevier Health Sciences, 2016.

JAIN, N. C. Essentials of Veterinary Hematology, $1^{\text {a }}$ ed. WileyBlackwell, Davis, 1993.

NELSON, R.; COUTO, C. G. Medicina interna de pequenos animais. Elsevier Brasil, 2015.

ROSENTHAL, R. C. Segredos em oncologia veterinária. Porto Alegre: Artmed, 2004.

SOARES, N. P., MEDEIROS, A. A., SZABÓ, M. P. J., GUIMARÃES, E. C., GUNDIM, L. F., SANTOS, T. R. Hemangiomas and hemangiosarcomas in dogs: retrospective study of 192 cases (2002-2014). Ciência Animal Brasileira, v. 18, 2017. Disponível em: <http://dx.doi.org/10.1590/1089-6891v18e-30889>. DOI: 10.1590/1089-6891v18e-30889

VALENCIANO, A. C.; COWELL, R. L. Cowell and Tyler's Diagnostic Cytology and Hematology of the Dog and Cat. Elsevier Health Sciences, 2013.

WONG, R. W., GONSAlVES, M. N., HUBER, M. L., RICH, L., STROM, A. Erythrocyte and biochemical abnormalities as diagnostic markers in dogs with hemangiosarcoma related hemoabdomen. Veterinary Surgery, v. 44, n. 7, p. 852857, 2015. Disponível em: <https://doi.org/10.1111/vsu.12361>. DOI: $10.1111 /$ vsu. 12361

ZACHARY, J. F.; MCGAVIN, M. D. Pathologic Basis of Veterinary Disease Expert Consult. Elsevier Health Sciences, 2016. 